\title{
Comparison of the Mode of Delivery between COVID and Non-COVID Pregnancies
}

\author{
Saima Najam ${ }^{1}$, Shehla Aqeel ${ }^{2}$, Syeda Ifra Hassan ${ }^{3}$ \\ ${ }^{1}$ FCPS (PAK) PG Certification in Medical Education (Dundee), Head of the OBGYN Department, Dr. Sulaiman \\ Al Habib Hospital, Sweidi, Riyadh, Saudi Arabia \\ ${ }^{2}$ Assistant Professor, Fatima Memorial Hospital, Lahore, Pakistan \\ ${ }^{3}$ Voluntary Worker, Student of IGSCE, Manarat Alriyadh International School, Riyadh
}

Corresponding Author: Saima Najam

\begin{abstract}
Background: The pregnant women and the newborn infants represent the vulnerable population in every society. Therefore Improvement efforts for the survival and the well being of the mothers and the neonates is indisputably a global priority especially during this pandemic of severe acute respiratory syndrome caused by a novel corona virus, called Covid-19 declared by the WHO ( World Health Association ) as global pandemic on March 11,2020. This pandemic has significantly altered the life styles of the pregnant women, boosting their apprehensions and concerns and importing great impacts on their health management. Current evidence suggests that the pregnant women are not at increased risk of Covid -19 as compared to the other adults. Similarly the condition is not severe in them. At the place of the current study the mode of delivery of the Covid patients is individualized and based on severity of the Covid infection and purely on the obstetric indications, as the evidence suggests that no mode of delivery is superior in terms of prevention of the vertical transmission.

Objective: We performed this study to compare the mode of delivery between the pregnant Covid and the non Covid pregnant population with the null hypothesis that the Covid effected pregnant patients are more prone to have caesarean section as compared to non Covid pregnant females and they are more prone to have CTG (cardiotocographic) abnormalities.

Material and Methods: It was a retrospective observational study done to compare the mode of delivery and the rate of CTG abnormalities in the study and the control group as the primary outcome. The secondary outcome was duration of active phase of the first stage, second and third stage of the labour between the pregnant Covid and the non Covid pregnant population for a period of 6 months (First January $2021-30^{\text {th }}$ June 2021) in labor ward of Dr. Sulaiman Al-Habib Hospital, Sweidi, Riyadh, Saudi Arabia. The study population comprised of 100 pregnant patients meeting our inclusion and exclusion criteria. The number of patients in each group was equal.

Results: No statistically significant difference was observed in the age, parity and ethnicity of both the groups. The rate of caesarean section was 38\% ( $n=19)$ in the Covid group while in the control group it was $10 \%(\mathrm{n}=05)$, the difference is statistically significant as shown by the P-Value of 0.004 . No significant difference in the CTG abnormalities was found in both the groups. However statistically significant reduction in the active phase of the first, second and third stage of labour was noted in the study population.

Conclusion: We hereby prove our null hypothesis that the Covid-19 effected pregnant patients are prone to have higher caesarean section rate, however no difference in rate of CTG (cardiotocographic) abnormalities was observed in both the groups. Significant reduction in the duration of all stages of the labour was also noticed which is a fruit of thought for the upcoming research.
\end{abstract}

Key words: Pregnancy, labour, caesarean section, Covid-19, duration of labour 


\section{INTRODUCTION}

The pregnant women and the newborn infants represent the vulnerable population in every society. Therefore improvement efforts for the survival and the well being of the mothers and the neonates is indisputably a global priority especially during this pandemic of severe acute respiratory syndrome caused by a novel corona virus, called Covid-19. ${ }^{(1)}$ declared by the WHO (World Health Association) as global pandemic on March 11,2020. ${ }^{(2)}$ This pandemic has significantly altered the life styles of the pregnant women, boosting their apprehensions and concerns and importing great impacts on their health management. (3) Current evidence suggests that the pregnant women are not at increased risk of Covid -19 as compared to the other adults. (4) Similarly the condition is not severe in them. ${ }^{(5,6)}$

At the place of the study the mode of delivery of the Covid patients is individualized and based on severity of the Covid infection and purely on the obstetric indications as the evidence suggests that no mode of delivery is superior in terms of prevention of the vertical transmission. ${ }^{(7)}$ It was observed in a recent study by Mullin and colleagues that $77 \%$ of the patients presenting in labor with Covid disease needs caesarean section, fetal distress was identified as most frequent reason for the caesarean. ${ }^{(8)}$ Few other studies suggest that the patients who were diagnosed as Covid positive have high incidence of caesarean section. ${ }^{(9-11)}$ Miller R and colleagues found no relation of the Covid -19 with the rate of caesarean section in New-York city. ${ }^{(12)}$

We performed this study to compare the mode of delivery between the pregnant Covid and the non Covid population with the null hypothesis that the Covid effected pregnant patients are more prone to have caesarean section as compared to non Covid pregnant females and are more prone to have $\mathrm{CTH}$ abnormalities.

\section{MATERIAL AND METHODS}

It was a retrospective observational study done to compare the mode of delivery and the rate of CTG abnormalities in the study and the control group as the primary outcome. The secondary outcome was the comparison of the duration of active phase of the first stage of labor from $5.0 \mathrm{~cm}$ till full cervical dilatation ${ }^{(13)}$ and the second and third stage of the labour. The secondary outcome was duration of active phase of the first stage, second and third stage of the labour between the pregnant Covid and the non Covid pregnant population for a period of 6 months (First January $2021-30^{\mathrm{TH}}$ June 2021) in labor ward of Dr. Sulaiman AlHabib Hospital, Sweidi, Riyadh, Saudi Arabia after getting the approval from the Institutional Review Board (IRB). The approval number allocated was RC21.08.21. Our hospital is a 350 bedded multidisciplinary hospital.

All women having nasopharyngeal swab positive in last 10 days and with singleton pregnancy in labour were included in the study. While the women with preterm labor, multiple pregnancy, any other medical disorder, and with Severe Covid disease requiring more than 15 litters of oxygen or on ventilator were excluded from the trial. All the laboring patients with Covid, meeting our inclusion and exclusion criteria were included in the study. For the formation of the control group the list was made of the non Covid patients, meeting the inclusion and exclusion criteria, and delivered during the same time period. Every $10^{\text {th }}$ patient was then enrolled to the trial. Once the two groups were formed the data was recorded on the pre designed proforma and analyzed by using SPSS version 26.

The primary and the secondary outcomes were compared between the two groups. The qualitative data was analyzed by using the Chi square Test while Student $t$ test was applied to the quantitative data. The $\mathrm{P}$ - value of 0.05 was considered as significant. 


\section{RESULTS}

We enrolled 100 patients to the trial, with 50 pregnant Covid positive patients in the study group and equal number of non Covid pregnant patients for the control group.

The mean age in the Covid and nonCovid group was 28 years and 26 years respectively. Similarly no significant difference was found in parity of the patients in both groups. Majority of the women in both the groups belonged to the Middle Eastern ethnicity, 92\% ( $\mathrm{n}=46)$ and 98\% $(n=49)$ in Covid and non Covid group respectively. So no significant difference in ethnicity was observed.

Table -1: EFFECT OF COVID ON MODE OF DELIVERY
\begin{tabular}{|l|l|l|l|}
\hline $\begin{array}{l}\text { MODE OF } \\
\text { DELIVERY }\end{array}$ & COVID & $\begin{array}{l}\text { NON } \\
\text { COVID }\end{array}$ & TOTAL \\
\hline SVD & $58 \%(\mathrm{n}=29)$ & $80 \%(\mathrm{n}=40)$ & $69 \%(\mathrm{n}=69)$ \\
\hline LSCS & $38 \%(\mathrm{n}=19)$ & $10 \%(\mathrm{n}=05)$ & $24 \%(\mathrm{n}=24)$ \\
\hline KIWI & $04 \%(\mathrm{n}=2)$ & $10 \%(\mathrm{n}=05)$ & $07 \%(\mathrm{n}=07)$ \\
\hline TOTAL & $100 \%(\mathrm{n}=50)$ & $100 \%(\mathrm{n}=50)$ & $100 \%(\mathrm{n}=100)$ \\
\hline
\end{tabular}

It was found in the current study that the rate of the caesarean section is higher in the Covid group as compared to the non Covid group, as shown in table 1. This difference was found statistically significant as demonstrated by the P-Value.(P-Value $=$ 0.004), after applying the Chi Square test.

The fetal distress manifested by the CTG abnormalities was found to be the most frequent indication of the caesarean section in both groups, as shown in table- 2 .

However the difference was not found to be statistically significant. (Pvalue $=0.201)$, when calculated after applying the Chi Square test.

\begin{tabular}{|c|c|c|c|}
\hline $\begin{array}{l}\text { CESSAREAN } \\
\text { PREGNANCIES }\end{array}$ & COVID & AND & COVID \\
\hline $\begin{array}{l}\text { INDICATION } \\
\text { OF CESAREAN }\end{array}$ & COVID & $\begin{array}{l}\text { NON } \\
\text { COVID }\end{array}$ & TOTAL \\
\hline $\begin{array}{l}\text { FETAL } \\
\text { DISTRESS }\end{array}$ & $\begin{array}{l}89.47 \% \\
(\mathrm{n}=17)\end{array}$ & $\begin{array}{l}93.33 \% \\
(\mathrm{n}=14)\end{array}$ & $\begin{array}{l}91.17 \% \\
(\mathrm{n}=31)\end{array}$ \\
\hline $\begin{array}{l}\text { FAILED } \\
\text { PROGRESS }\end{array}$ & $\begin{array}{l}10.52 \% \\
(\mathrm{n}=02)\end{array}$ & $\begin{array}{l}06.66 \% \\
(\mathrm{n}=1)\end{array}$ & $\begin{array}{l}08.8 \% \\
(\mathrm{n}=03)\end{array}$ \\
\hline TOTAL & $\begin{array}{l}100 \% \\
(\mathrm{n}=19)\end{array}$ & $\begin{array}{l}100 \% \\
(\mathrm{n}=15)\end{array}$ & $\begin{array}{l}100 \% \\
(\mathrm{n}=34)\end{array}$ \\
\hline
\end{tabular}

The duration of the labour was also compared in both the groups. The significant reduction in the duration of the first stage (active phase) can be seen, as shown in the figure below. The difference was found statistically very significant as the P-Value when calculated after applying independent $\mathrm{T}$ test was 0.002 .

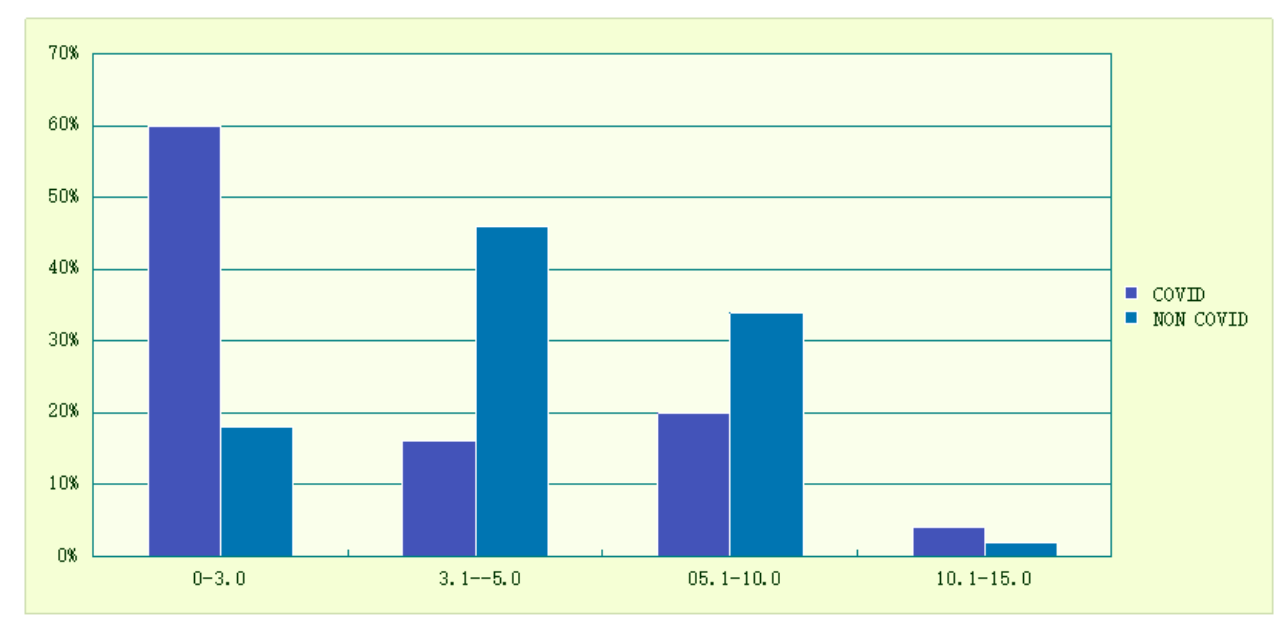

FIGURE -1: EFFECT OF COVID ON DURATION OF THE FIRST STAGE ( ACTIVE PHASE) OF LABOUR

Similarly significant reduction in the duration of the second stage of the labour was observed in the study population as $94 \%(n=47)$ of the patients delivered within 30 minutes of full cervical dilatation where as only $36 \%(\mathrm{n}=18)$ patients delivered in the first 30 minutes in the control group. As shown in the figure-2. The calculated PValue after applying the independent $\mathrm{T}$ test was 0.002 which shows that the difference is statistically significant. 


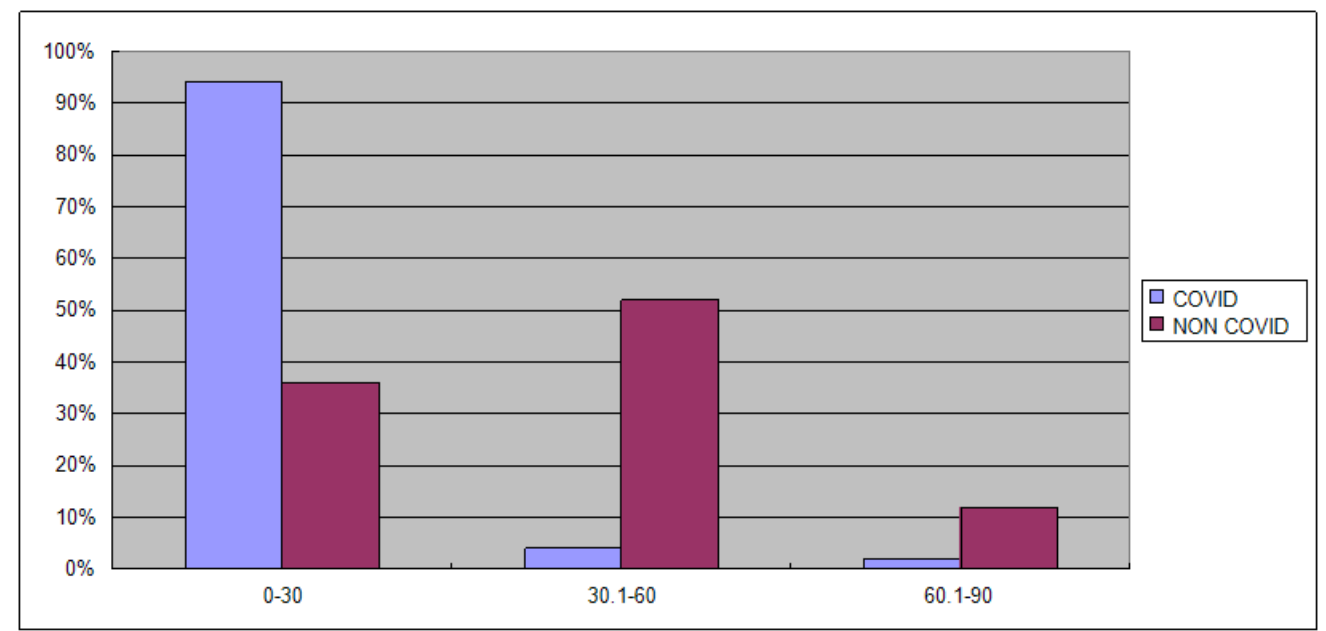

FIGURE -2: EFFECT OF COVID ON DURATION OF THE SECOND STAGE OF LABOUR

Regarding the duration of the third stage of the labour it was observed that $100 \%$ of the patient in both the groups delivered the placenta within 25 minutes. No case of retained placenta was noticed.

However in the study group 94\% $(n=47)$ of the patients delivered the placenta within 5 minutes, while in the control group the rate was $34 \%(n=17)$ only. The duration of third stage of labour was 5-10 minutes in $04 \%(n=02)$ of the Covid positive patients in comparison to $20 \%(\mathrm{n}=10)$ in the non-Covid group. Only $02 \% \quad(n=1)$ of the patients among the study population had the third stage duration of more than 10 minutes while in the control group it was $46 \%(n=43)$. The independent $T$ test was applied and the P-value was found to be 0.000 which shows that there is significant reduction in the duration of the third stage of labour in Covid patients.

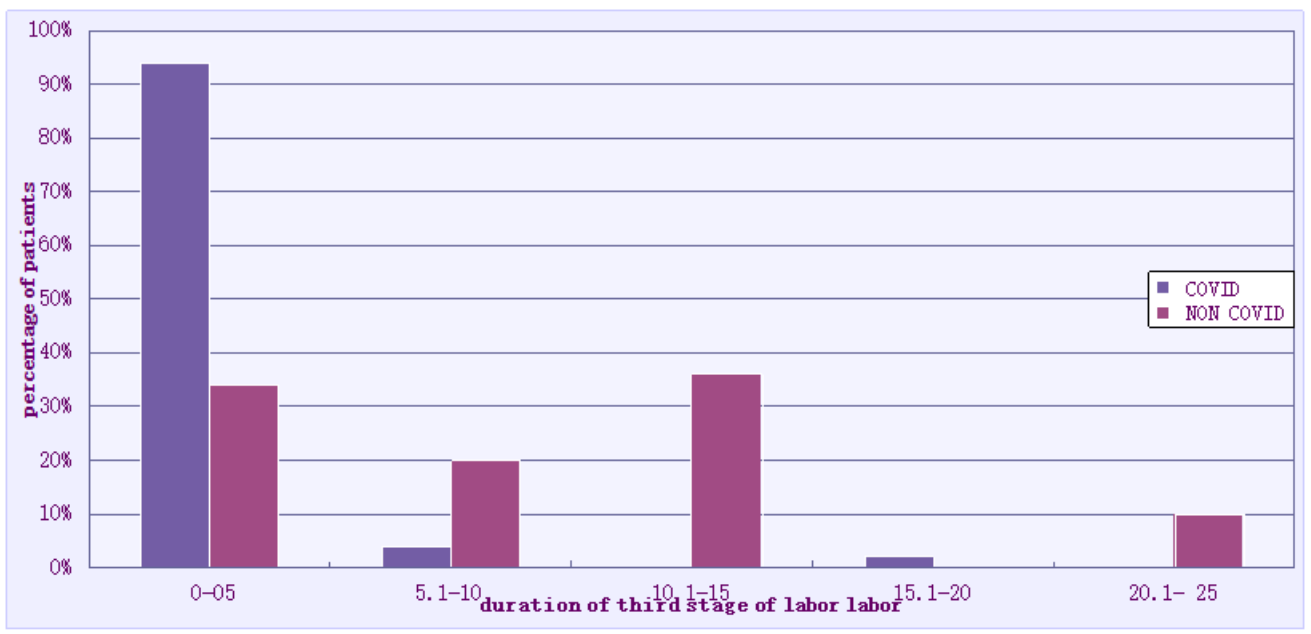

Figure: 3 EFFECT OF COVID ON THIRD STAGE OF LABOUR

\section{DISCUSSION}

There is no doubt that the caesarean section in the pregnant women affected by Covid and having mild to moderate disease should be only for the obstetric indications. ${ }^{(7)}$ It was observed in the current study that the rate of caesarean section was significantly higher in the study group as compared to the control group. Our results are supported by the findings of Mullin and colleagues who found a high percentage of Covid patients delivered by the caesarean section. (8) To support our observations further, we quote here the work of Noelle and colleagues ${ }^{(9)}$ and Nunzia and colleagues (10) in New York who also found that the patients affected by Covid-19 need caesarean section in majority of the cases. 
The observations of Lian $\mathrm{C}$ and colleagues (11) also supported the results of the current study.

In contrast to the observations of the current study, Miller $\mathrm{R}$ and colleagues found no relation of the Covid -19 with the rate of caesarean section in New-York city, their data suggested that the Covid -19 infection does not affect the route of the delivery. ${ }^{(12)}$

On the other hand Ashokka and colleagues suggested that in the laboring patients with Covid 19 the thresh hold of the caesarean section should be kept lower than the usual so that the infection control procedures can be more readily adhered to and the transmission of the disease is minimized. ${ }^{(14)}$ In another study in Spain it was found that the patients having mild symptoms have excellent outcomes after vaginal birth as compared to the patients delivered by caesarean section. ${ }^{(15)}$ Arab and colleague also support the concerns raised in Spain for low thresh hold of caesarean in Covid patients and advocate the vaginal delivery as they have observed that it decreases the risk of clinical deterioration of the patients, Covid associated thromboembolism and neonatal morbidity associated with iatrogenic preterm deliveries. ${ }^{(16)}$

It was observed in the current study that that the rate of fetal distress manifested by the CTG abnormalities was not significantly different in both the Covid and Non Covid pregnant patients, which was in contrary to the findings of Mullin and colleagues who observed that the fetal distress was the most frequent reason for the caesarean section. ${ }^{(8)}$

Contrary to our results Bonfil and colleagues also found that the Covid effected pregnancies are more prone to develop fetal heart rate changes detected on cardiotocography ${ }^{(18)}$ Juan and colleagues also observed that there is increased rate of fetal distress manifested by either cardiotocographic abnormalities or the meconium stained liquor in Covid pregnancies ${ }^{(17)}$ which can lead to increased rate of caesarean section.

There is not much data available about the duration of different stages in Covid patients however in the case reports by Cao and colleagues ${ }^{(19)}$ one of the patient was admitted at $5.0 \mathrm{~cm}$ dilatation and the duration of the first and second stage of the labour was recorded as 68 minutes only, which also supports the shorter duration of the labour, observed in the current study in the effected patients. However more evidence is awaited.

\section{CONCLUSION}

We hereby prove our null hypothesis that the Covid-19 effected pregnant patients are prone to have higher caesarean section rate, however no difference in rate of CTG (cardiotocographic) abnormalities was observed in both the groups. Significant reduction in the duration of all stages of the labour was also observed which is a fruit of thought for the upcoming research. As it is proved that the rate of caesarean section is higher in patients with Covid so all patients should be referred to the tertiary care centers for the delivery.

\section{ACKNOWLEDGMENT}

The authors want to acknowledge the cooperation of the infection control team and all the nurses and the residents of the labor ward for their collaboration and support in collecting data.

\section{Strengths and Limitations:}

To the best of our knowledge this is the first study in which the duration of labor was compared between the Covid and the non Covid pregnancies, however the study was done in a single Centre and was retrospective. The number of patients in the study is also limited. In future a multicentric prospective study with higher number of patients is required to further confirm the results. 


\section{Authors' Contribution:}

NS: Concept and design of the study, acquisition and analysis of data, drafting the manuscript, final approval of the manuscript.

HI: Data collection and drafting the manuscript.

AS: Analysis and interpretation of data.

Conflict of Interest: None to declare

Source of Funding: None to declare

\section{Ethical Approval: Approved}

\section{REFERENCES}

1. Graham WJ, Afolabi B, Benova L, Campbell OMR, Filippi V,Nakimuli A, etal. Protecting hard-one gains for mothers and newborns in low income and middle income countries in the face of Covid-19: call for a service safety net. BMJ Glob Health: 2020 October 3; cited 2021 June 10. Available from https://doi.org/10.1136/bmjgh-2020002754

2. WHO Director-General's opening remarks at the media briefing on Covid-19- March 2020.

3. Zhang J, Zhang Y, Ma Y, Ke Y, Huo S,He $\mathrm{L}$, et al. The associated factors of cesarean section during Covid- 19 pandemic: a cross sectional study in nine cities of China. Environmental health and preventive medicine: 2020 October 10; cited 2021 June 10. Available from https://doi.org/10.1186/s12199-020-00899w

4. Rasmussen SA, Smulian JC, Lednicky JA, Wen TS, Jamieson DJ. Coronavirus disease 2019(Covid-19) and pregnancy: what obstetricians need to know. Am J Obstet Gynecol.2020;222:415-26.

5. Qiao J. What are the risks of Covid-19 infection in pregnant women? Lancet 2020;395:760-2.

6. Najam S, Malik SE, Hassan SI, Ahmed MM, Shireen A, Clinical analysis and perinatal outcome in pregnant patients with Covid-19. Int J Health Sci Res. 2021; 11(6): 72-8.

7. Cai J, Tang M, Gao Y, Zhang H, yang Y, Zhang D, et al. Cesarean section or vaginal delivery to prevent possible vertical transmission from a pregnant mother confirmed with Covid-19 to a neonate: A systemic review.Review. Front. Med. 2021 February 17; cited 2021 June 11. Available from http://10.3389/fmed.2021.634949

8. Mullins E, Evans D, Viner RM, Obrien P, Morris E. Corona virus in pregnancy and delivery: rapid review. Ultrasound Obstet Gynecol,2020;55:586-92.

9. Noelle B, Caitlin B, Cyanthia GB, Russel M, Rebecca M, Kyra B, et al. Corona virus disese 2019 infection among asymptomatic and symptomatic pregnant women: two weeks of confirmed presentations to an affiliated pair of New York city hospitals. Am J Obstet Gynecol MFM.2020 April 9; cited 2021 June 11. Available from https://doi.org/10.1016/j.ajogmf.2020.10011 8.

10. Nunzia DGA, Oberta R, Gianluigi P, Giuliana S. Covid-19 during pregnancy: a systemic review of reported cases. Am J Obstet Gynecol, 2020;223(1):36-41.

11. Lian C, Quin L, Danni Z, Hai J, Yuan W, Li $\mathrm{Z}$, et al. Clinical characteristics of pregnant women with Covid-19 in Wuhan China. N Engl J Med.2020;382(25).

12. Malhotra Y, Miller R, Bajaj K, Sloma A, Wieland D. No change in cesarean section rate during Covid-19 pandemic in New York Citu. Eu J of Obstet Gynecol and Reprod Bio.2020;253:328-9.

13. Zhang J, Troendle J, Mikolajczyk R, et al. The natural history of the normal first stage of labor. Obstet Gynecol. 2010;115(4): 70510.

14. Ashokka B, Loh MH, Tan CH, SuLL, Young BD, Lye DC, et al. Care of the pregnant woman with coronavirus disease 2019 in labor and delivery: anesthesia, emergency cesarean delivery, differential diagnosis in the acutely ill parturient, care of the new born and protection of the health care personnel. AJOG: 2020 April 03; cited 2021 June 11. Available from https://doi.org/10.1016/j.ajog.2020.04.005.

15. Martinez- Perez O, Vouga M, Cruz MS, Forcen AL, Pnchaud A, Munoz-Chapuli M, et al. Association between mode of delivery among pregnant women with Covid-19 and maternal and neonatal outcome in Spain. JAMA. 2020;324(3):296-9.

16. Arab W, Atallah D. Cesarean section rates in the Covid-19 era: false alarms and the 
safety of the mother and the child. Eu J Midwifery. 2021; 05: 14-5.

17. Juan J, Gil MM, Rong Z, et al. Effect of corona virus disease 2019(Covid-19) on maternal perinatal and neonatal outcome: systemic review. Ultrasound Obstet Gynecol 2020;56:15-27.

18. Bonfil AGP, Perez OM, Llurba E, et al. Fetal heart rate changes on the cardiotocograph trace secondary to maternal
Covid-19 infection. Eur J of Obstet Gynecol Reprod Bio, 2020;252:286-93.

19. Cao D, Chen M, Peng M, Yen H, Sun G. Vaginal delivery in women with covid-19: report of two cases. BMC Preg and child birth,2020;20:580-5.

How to cite this article: Najam S, Aqeel $S$, Hassan SI. Comparison of the mode of delivery between COVID and Non-COVID pregnancies. Int J Health Sci Res. 2021; 11(9): 277-283. DOI: https://doi.org/10.52403/ijhsr.20210942

$* * * * * *$ 